\title{
The Humanitarian Action Qualifications Framework: a quality assurance tool for the Humanitarian Sector
}

\author{
Bastiaan L. Aardema and Cristina Churruca Muguruza*
}

\begin{abstract}
The article presents the European Universities on Professionalisation on Humanitarian Action (EUPRHA) Project as an initiative that seeks to contribute to the professionalisation and quality assurance of the humanitarian sector. Its purpose is to explain the approach and the process leading to the development of the Humanitarian Action Qualifications Framework as an example of good practice for other sectors aiming at improving the recognition of qualifications as a precondition of academic and professional mobility. With this aim, it introduces the educational and humanitarian trends that led to this project: the move from transnational qualifications frameworks of which the European Qualifications Framework for Lifelong Learning (EQF) is the best example to sectoral qualifications frameworks and the increasing demand from the sector seeking to determine the competencies and required skills of a professional humanitarian aid worker. Based on the EQF and the Tuning methodology the framework will act as a translating device to make national and sectoral qualifications more readable and promote humanitarian workers' and learners' mobility between countries and organisations. It will facilitate inter-system transparency and recognition of (non-)formal and informal learning by linking occupations, skills, competences, and qualifications, thus benefiting the Humanitarian Sector as a whole.
\end{abstract}

Keywords: humanitarian action; emergencies; disasters; sectoral qualifications frameworks; sectoral profiles; meta-profiles; lifelong learning, learning outcomes; competences.

\section{Introduction}

Over the past decade, many policy developments have taken place within Europe and worldwide to provide important points of reference for setting and

* Bastiaan L. Aardema (b.l.aardema@rug.nl, University of Groningen, the Netherlands) and Cristina Churruca Muguruza (cristina.churruca@deusto.es, Universidad de Deusto, Spain) lead the work package responsible for setting up a qualifications framework for the humanitarian sector in the EUPRHA project. It is a Lifelong Learning Academic Network coordinated by the University of Deusto. This project has been funded with support from the European Commission. This publication reflects the views only of authors and the Commission cannot be held responsible for any use which may be made of the information contained therein. 
assessing learning standards in education understood as a lifelong learning process thereby including general education, vocational education and training, higher education, as well as informal and non-formal learning. Qualifications frameworks are considered one of the tools for better recognition of qualifications provided by learning programmes. Improving the transparency and understanding of qualifications systems, they transmit the signal that qualifications possess about a person's knowledge, skills and competences to those who need to receive it. ${ }^{1}$ In order to promote geographical and labour market mobility as well as lifelong learning, the European Qualifications Framework for Lifelong Learning (EQF) has been designed to act as a reference for different qualifications systems and frameworks in Europe. ${ }^{2}$

Conceived by dr. Julia González, the European Universities on Professionalisation on Humanitarian Action (EUPRHA) Project arose in this context of intensive developments in the area of qualifications frameworks as an initiative that seeks to contribute to the professionalisation and quality assurance of the humanitarian sector. ${ }^{3}$ One of the major problems stopping the flow of trained people within the humanitarian sector concerns the creation of certification and recognition systems necessary for professionalisation. As a study of the humanitarian professional sector pointed out "in a sector where consistent humanitarian occupational standards do not exist, several NGOs, INGOs, learning providers and universities have unilaterally moved, over the years, to address the learning and capacity building needs of workers based on their particular interpretations of identified needs. This has led to an ad hoc training offering, with gaps in provision and a lack of pathways and progression routes for the sector, both for those wishing to enter the sector and those wishing to develop professionally within the sector". ${ }^{4}$

${ }^{1}$ On the meaning and development of qualifications frameworks and particularly on transnational ones see: Keevy, Chakroun, and Deij, Transnational Qualifications Frameworks, 2011.

2 A key characteristic and a specificity of the European qualifications frameworks and systems' landscape is the existence of two levels of frameworks: European meta-frameworks which act as a common reference and national qualifications frameworks (NQF) which are rooted in the specificities of national systems. One of two European meta-frameworks is the European Qualifications Framework for Lifelong Learning - EQF. The other covers higher education qualifications only: the Qualifications Framework for European Higher Education Area. These meta-frameworks are compatible: they are both based on the use of learning outcomes to define qualifications and their levels.

${ }^{3}$ EUPRHA is an Academic Network financed by the European Commission Lifelong Learning programme that links universities in all European countries, the core the NOHA Network, and humanitarian practitioners (International Council of Voluntary Agencies (ICVA and SPHERE) to contribute to the professionalisation of the Humanitarian Sector.

${ }^{4}$ Walker and Russ, Professionalising the Humanitarian Sector. 
In this context, the EUPRHA Project developed the Humanitarian Action Qualifications Framework, which aims at becoming a common reference system based on learning outcomes and acting as a translating and classifying device of qualification levels and systems throughout the humanitarian sector. The framework focuses on lifelong learning, thereby including general education, vocational education and training, higher education, as well as informal and non-formal learning. It intends to act as a neutral reference point for all different types of qualifications in the humanitarian sector in order to assist in the identification of potential progression routes in the context of lifelong learning and to support workers and learners mobility within the humanitarian sector and across sectors.

The purpose of this article is to explain the approach of the project and the process leading to the development of the Humanitarian Action Qualifications Framework as an example of good practice for other sectors aiming at improving the recognition of qualifications as a precondition of academic and professional mobility. In order to put it into context it first introduces the move from European to sectoral qualifications frameworks, as well as the humanitarian sector where there has been an increasing focus on competencies and required skills in the attempt to professionalise the sector and determine what a humanitarian aid worker should be capable of. However, these frameworks that focus on professional competencies are not always expressed in terms of learning outcomes and do not, most of the times, distinguish between different levels. Moreover, they do not refer to any qualifications frameworks neither European nor national and therefore, they do not facilitate the translation and the comparison of qualifications between countries and sectors.

\section{The move from European to Sectoral Qualifications Frameworks}

The European Qualifications Framework was developed in reaction to requests from the Member States, the social partners and other stakeholders for a common reference to increase the transparency of qualifications. The Lisbon European Council in 2000 concluded that increased transparency of qualifications should be one of the main components necessary to adapt education and training systems in the European Union to the requirements of a knowledge society. In 2002 the Barcelona European Council called for closer cooperation in the university sector and improvement of transparency and recognition methods in the area of vocational education and training. As a consequence the Council Resolution of 27 June 2002 on lifelong learning invited the Commission, in close cooperation with the Council and Member 
States, to develop a framework for the recognition of qualifications for both education and training, building on the achievements of the Bologna Process and promoting similar action in the area of vocational training. ${ }^{5}$ It recognised that lifelong learning is often obstructed by a lack of communication and cooperation between the various education providers and competent bodies in both general and vocational education and training, and at the different levels within and between countries. This has resulted in unnecessary barriers for people to access training and continue training. ${ }^{6}$

The Council resolution led to the declaration by the European Ministers responsible for vocational education and training, the Commission and the European social partners at their meeting in Copenhagen in November 2002 for a strategy to improve the performance, quality and attractiveness of vocational education and training, commonly referred to as the 'Copenhagen Process'. In March 2005, the EU Heads of Government formally requested the development of a European Qualifications Framework (EQF) based on the work carried out by the European Commission. In the context of the Bologna Process, the conference of ministers responsible for higher education held in Bergen in May 2005 underlined the importance of ensuring complementarity between the framework for the European Higher Education Area and the proposed EQF. Finally, in the context of the revised Lisbon Strategy, also the Employment Guidelines 2005-2008 stressed the need to ensure flexible learning pathways and to increase opportunities for the mobility of students and trainees, by improving the definition and transparency of qualifications, their effective recognition and the validation of non-formal and informal learning. ${ }^{7}$

Thus, the EQF was foreseen as a framework that would combine three important areas of policy-making: the Bologna Process (1999), the Lisbon Strategy (2000) and the Copenhagen Process (2002). The Lisbon Strategy aimed to make the European Union the most competitive and dynamic knowledge-based economy in the world capable of sustainable economic growth with more and better jobs and greater social cohesion. The lifelong learning component of the Lisbon Strategy demanded a challenging reform and modernisation of education systems in each Member State with the aim that by 2010 Europe should have become world leader in terms of the quality of its education and training systems. In order to realise this, the member states were required to make sure that there is a constant renewing of

5 “Council Resolution of 27 June 2002 on Lifelong Learning (2002/C 163/01),” 1.

${ }^{6}$ Ibid.

${ }^{7}$ Implementing the Community Lisbon Programme. Proposal for a Recommendation of the European Parliament and of the Council on the Establishment of the European Qualifications Framework for Lifelong Learning. 
knowledge, skills and wider competences in the labour force and that there are as few obstacles as possible to access education and training and to continue developing previously acquired knowledge, skills and competences in a Member State or between Member States. The EQF is seen as instrumental to achieve all these objectives. ${ }^{8}$

The Commission's consultation paper on the envisioned EQF came out in July 2005 and was submitted to an extensive EU-wide consultation process. The draft proposed an eight level framework based on learning outcomes aiming to facilitate the transparency of qualifications and to support lifelong learning. It outlined an overarching framework to be set up in Europe to facilitate comparison of qualifications and qualification levels. It was presented as a meta-framework, that would facilitate relating different qualifications frameworks to each other and also allow for comparisons between individual qualifications. ${ }^{9}$ Such comparisons would constitute the basis of greater recognition and transfer of achieved learning outcomes in the form of qualifications acquired by individuals and should facilitate the mobility of learners and workers across Europe. The EQF was intended to be fully voluntary in the sense that Member States were able to decide themselves whether or not to relate their national systems to it. ${ }^{10}$

The consultation concerning the Commission's proposal showed widespread support among the stakeholders but also resulted in a request for greater simplification. The Commission adopted a revised proposal on 6 September 2006, which was subsequently negotiated in the European Parliament and the Council during 2007, resulting in the EQF's formal adoption. ${ }^{11}$ Following the adoption in April 2008, a process of implementation started. ${ }^{12}$ The EQF represented a new approach to European cooperation in the field of qualifications. The introduction of a set of learning outcomes based on levels and descriptors spanning all forms of qualifications and the entire range of qualification levels had not been attempted previously. Therefore, its implementation required that all stakeholders shared a clear understanding of its objectives and main functions, the principles and logic applied when defining it, and the requirements for implementation in terms of stakeholders involvement, transparency, quality assurance and peer review. ${ }^{13}$

${ }^{8}$ Keevy, Chakroun, and Deij, Transnational Qualifications Frameworks, 2011, 18-19.

${ }^{9}$ Explaining the European Qualifications Framework for Lifelong Learning.

${ }^{10}$ Keevy, Chakroun, and Deij, Transnational Qualifications Frameworks, 2011, 21.

11 Ibid.

12 "Recommendation of the European Parliament and of the Council of 23 April 2008 on the Establishment of the European Qualifications Framework for Lifelong Learning," 1.

${ }^{13}$ Explaining the European Qualifications Framework for Lifelong Learning. 
One of the issues raised during the consultation was how sectoral qualifications emerging at international level could be linked to the EQF and national qualifications frameworks. The question of 'sectoral qualifications frameworks' has risen in some sectors in recent years and also in European multinationals. ${ }^{14}$ Some sectors have set up European projects concerning a sectoral implementation of the EQF: Sports and Active Leisure sector, Tourism sector, Automotive sector, Chemistry Industry, ICT sector, Construction Industry, Metal and Electrical Industry. ${ }^{15}$

Another approach has been the one adopted by the Tuning Project in 2008. The Tuning experts' group identified two main issues: "two competing frameworks for the Higher education sector, one based on stand-alone descriptors and the other one on cumulative descriptors and the challenge to bridge the two meta-qualifications frameworks and the Tuning reference points or meta-profiles at subject area level". ${ }^{16}$ To overcome this challenge, the solution found was to develop sectoral qualifications frameworks as a link between the subject area level and the meta-level. A sector is understood by Tuning as a combination of related fields of study which are based on more or less comparable learning profiles. Five to six sectors were distinguished: Humanities and the Creative and Performing Disciplines, Engineering, Natural Sciences, Health Care and Social Sciences. ${ }^{17}$ While being inspired by the Tuning approach, the set-up of these frameworks follows the logic of EQF levels, though not in all cases all eight EQF-levels could be addressed. Within this constellation, Tuning developed sectoral qualifications frameworks for the Social Sciences in 2010 and for the Humanities and for the Creative and Performing Disciplines in 2012. ${ }^{18} \mathrm{In}$ addition, these projects resulted in the development of reference points for Art History, Linguistics, Literary Studies, Theology and Religious Studies, as well as level descriptors for Architecture, History, Music, Visual and Performing Arts. ${ }^{19}$

The sectoral qualifications frameworks for the Social Sciences, the Humanities and the Performing Arts have served all three as informative examples for the Humanitarian Action Qualifications Framework in terms of

${ }^{14}$ European Qualifications Frameworks, National Qualifications Frameworks, Higher Education, State of Play, 6; International Qualifications, 8.

${ }^{15}$ European Qualifications Frameworks, National Qualifications Frameworks, Higher Education, State of Play, 6; see in this regard: International Qualifications.

${ }^{16}$ Wagenaar, "Columbus' Egg?," 82.

17 Ibid., 83.

18 Tuning Sectoral Framework for Social Sciences; Tuning Sectoral Qualifications Frameworks for the Humanities and the Arts. Final Report 2010-2011.

19 "SQF Humanities and Arts: Outcomes." 
their internal setup, formulation and organisation and their influence can be traced back in the setup of the Humanitarian Action Qualifications Framework and particularly the EUPRHA Profile.

\section{The humanitarian sector ${ }^{20}$}

The humanitarian sector is extremely difficult to define due to its constant evolution, changes and the many different - sometimes even opposite - points of view and definitions expressed by both scholars and practitioners. As Walker and Maxwell expressed, "its complexity of origins, multitude of players and ever-varying environment make humanitarianism a challenging system to describe and understand and an even more challenging system to predict where the system will go". ${ }^{21}$ The notions of "humanitarian action' and 'humanitarian system' have almost as many definitions as authors, organisations and institutions have defined them. Indeed, as Borton says, "a striking feature of the humanitarian system is the continuing lack of clarity as to what the 'humanitarian system' actually consists of and where its boundaries lie". ${ }^{22}$

Humanitarian action has grown into a multibillion dollar industry with capacity to cope with complex emergencies affecting millions of human beings worldwide. Just to have an idea of its size, as many sources such as ALNAP or Development Initiatives describe, the collective international government response to humanitarian crises reached an historic peak in 2010, growing by $10 \%$ to reach US $\$ 13$ billion. ${ }^{23}$ Although financial flows have slowed down during the last two years due to the global financial crisis, it is estimated that there are some 4,400 non-governmental organisations worldwide undertaking humanitarian action on an ongoing basis and an estimated total of 274,000 humanitarian workers worldwide. ${ }^{24}$ To these figures could be added those of governments, corporations, military, etc. that would result on a final still undetermined number of hundreds of thousands of individuals.

Thus, this sector has become a massive community of stakeholders and actors, who interact, collaborate, coordinate and sometimes even

${ }^{20}$ This section draws on the report developed by the EUPRHA project identifying current trends in the humanitarian sector: The State of Art of Humanitarian Action. A Quick Guide on the Current Situation of Humanitarian Relief, Its Origins, Stakeholders and Future.

${ }_{21}$ Walker and Maxwell, Shaping the Humanitarian World, 136.

${ }_{22}$ Borton, Future of the Humanitarian System, 4.

${ }^{23}$ GHA Report 2012, 6.

${ }^{24}$ Taylor et al., The State of the Humanitarian System, 9, 26. 
compete to succeed on their main objective: protecting lives and dignity of vulnerable populations and communities affected by natural disasters and conflicts all over the globe. Humanitarian aid is generally considered a fundamental expression of the universal value of solidarity between people and a moral imperative. It has many different definitions depending on authors, and reflecting the diversity of organisations and institutions. Nonetheless, the main part of the academia and the humanitarian community has a shared understanding on the aim of humanitarian action. For instance, the European Consensus on Humanitarian Aid provides a common vision that guides the action of the European Union, both at its Member States and Community levels, in humanitarian aid in third countries and is supported by the main European humanitarian nongovernmental organisations. It defines the aim of humanitarian aid as being "to provide a needs-based emergency response aimed at preserving life, preventing and alleviating human suffering and maintaining human dignity wherever the need arises if governments and local actors are overwhelmed, unable or unwilling to act." ${ }^{25}$

In the same line according to the Development Assistance Committee of the Organisation for Economic Cooperation and Development - which brings together the main international aid donors - "humanitarian aid is assistance designed to save lives, alleviate suffering and maintain and protect human dignity during and in the aftermath of emergencies". ${ }^{26}$

It was understood during the last two decades that as the responsibilities of humanitarians increase, so must their accountability and professionalisation. With regard to accountability, Walker and Russ mention that "humanitarian assistance is [now] much more centre-stage, politically, than it was two decades ago and the regulatory frameworks of most nations now demand higher accountability from all public service providers, particularly for the spending of taxpayers' money". ${ }^{27}$ In addition, the humanitarian system understood that it was not only accountable to its donors, but more importantly, it should be accountable to the populations it assists. Although this idea has been in place for many years now, the rise of information and communication technologies are enabling affected communities to have finally "more of a voice and to start to demand a greater sense of accountability from those who provide vital services to

25 "Joint Statement by the Council and the Representatives of the Governments of the Member States Meeting within the Council, the European Parliament and the European Commission (2008/C 25/01) The European Consensus on Humanitarian Aid," 1.

${ }^{26}$ DAC Statistical Reporting Directives, para. 184.

27 Walker and Russ, "Fit for Purpose," 1209. 
them". ${ }^{28}$ As per professionalisation, as Walker and Russ say, "it is clear that many of the elements of professionalisation are in place or developing". ${ }^{29}$

Accountability and professionalisation are much more needed nowadays than ever as humanitarians face new challenges. Humanitarian stakeholders are increasingly concerned about the impacts of current or emerging global challenges, such as climate change, food crises and financial crises, extreme poverty, urbanisation, water scarcity, energy security, migration and population growth, on the caseloads that humanitarian agencies work with and the operational environments they will have to work in. To anticipate the evolution of these challenges, promoted by various political, economic, legal, demographic, environmental, and technological factors, is a very complex task. Their individual and combined impacts are already shaping, and will continue to shape international humanitarian action and set new requirements for knowledge, skills and competences.

A characteristic of the humanitarian sector is the need for recognition of professional qualifications and non-formal and informal learning to allow the mobility within and across sectors. As a consequence of humanitarian action being a relatively young domain, many humanitarian professionals started their careers in different disciplines. Furthermore, aid workers locally recruited in humanitarian crises who received most of their professional humanitarian training on-the-job while working for (international) humanitarian agencies have expressed their interest in entering the humanitarian sector and have their work experience and learning development indeed recognised. An important initiative that already aimed at addressing this demand has been the Humanitarian Passport Project for instance. ${ }^{30}$

\section{Project approach: the Tuning methodology and the EQF}

The methods of the project are based on two different, but complementary approaches: the Tuning methodology and the European Qualifications Framework for Lifelong Learning (EQF). The Tuning methodology was formulated by the Tuning Educational Structures in Europe that started in 2000 and was initiated as a response from the universities to the Bologna Process and at a later stage the Lisbon Strategy in the higher educational area of Europe. Its main approach is to (re-)design, develop, implement, evaluate

\footnotetext{
${ }^{28}$ Ibid.

${ }^{29}$ Ibid.

${ }^{30}$ Humanitarian Learning and Development Passport.
} 
and enhance quality of first, second and third cycle degree programmes (e.g. Bachelor, Master and PhD programmes) in the European Higher Education Area. In that process, Tuning reflects the idea that universities should not look for uniformity in their degree programmes or should pursue unified, prescriptive and definitive European curricula, but that they should look for points of reference, commonalities, convergence and common understanding in order to preserve the rich educational diversity in Europe while facilitating mutual legibility and comparability of curricula, structures, programmes and actual teaching. ${ }^{31}$

While the core of the Tuning methodology focused initially on generic competences, subject-specific competences, the role of ECTS-credits as an accumulation system, the approaches to learning, teaching and assessment, as well as the role of quality enhancement in the educational process, it has also focused on module learning outcomes and programme learning outcomes and how these are related to the level descriptors of the first, second and third cycles in the European Higher Education Area. ${ }^{32}$

Where the Tuning methodology searches for commonalities shared between educational programmes in higher education, the European Qualifications Framework for Lifelong Learning has a different approach in that it focuses on all kinds of learning (formal, non-formal and informal) throughout a learner's education and career. Likewise, it does not concentrate so much on establishing commonalities but more on defining levels of learning for qualifications. In a European context where each state controls its own educational system and range of qualifications, the EQF is a meta-qualifications framework to which both national and sectoral qualifications frameworks can relate. This way the EQF helps making qualifications more readable and understandable across different countries and systems in Europe. ${ }^{33}$ Central to the EQF is a table contrasting eight rows of levels of learning and describing these in the form of learning outcomes. The learning outcomes themselves are structured into three columns, making a distinction between knowledge, skills and competence.

\section{The EQF Descriptors}

The knowledge, skills and competence descriptors have in the EQF context a particular meaning. The three categories are in themselves the

31 "Tuning Educational Structures in Europe."

32 "Tuning Methodology."

${ }^{33}$ See for more details: "European Qualifications Framework. 
result of a pragmatic agreement between various, common ways of differentiating learning outcomes. National and sectoral frameworks or systems that have to incorporate different approaches, specific traditions and needs are therefore allowed to diverge from this if necessary. ${ }^{34}$ In the context of the humanitarian sector, there do not seem to be imperative reasons to use another descriptor categorisation. For one, humanitarian action is still a relatively new field without strong, ingrained traditions concerning how qualifications of humanitarian aid workers should be described and secondly, the EQF descriptors are already a pragmatic compromise between different national traditions.

The descriptors knowledge and skills normally don't present much difficulty in understanding. In EQF terms, knowledge is defined as "the outcome of the assimilation of information through learning" and consists of "the body of facts, principles, theories and practices that is related to a field of work or study". ${ }^{35}$ In essence, the descriptor describes what you know, which can be both theoretical and/or factual. Skills are defined as "the ability to apply knowledge and use know-how to complete tasks and solve problems". In essence, this descriptor describes what you can do, which can be described as "cognitive (involving the use of logical, intuitive and creative thinking) or practical (involving manual dexterity and the use of methods, materials, tools and instruments)" ${ }^{36}$ Together with knowledge resources, skills form the instruments in one's toolbox that are required for resolving certain tasks or issues.

Understanding the descriptor 'competence' requires more effort and its present meaning is the outcome of several debates on different alternatives to capture a dimension that only indirectly links to knowledge and ability. ${ }^{37}$ In its present EQF form, the label 'competence' has a particular meaning that differs from what some would consider the customary meaning of 'competence' in the English language. Instead, 'competence' is described in terms of responsibility and autonomy and the descriptor is defined as "the proven ability to use knowledge, skills and personal, social and/or methodological abilities, in work or study

${ }^{34}$ Explaining the European Qualifications Framework for Lifelong Learning, 5."

35 "Recommendation of the European Parliament and of the Council of 23 April 2008 on the Establishment of the European Qualifications Framework for Lifelong Learning," sec. Annex I.

${ }^{36}$ Ibid.

${ }^{37}$ Markowitsch and Luomi-Messerer, "Development and Interpretation of Descriptors of the European Qualifications Framework.," 43-45. 
situations and in professional and personal development". ${ }^{38}$ In essence, this descriptor describes in which situations you can work and to a certain extent still alludes to the professional conduct and the wider competences displayed in terms of attitudes, behaviour and initiative necessary for operating professionally, even though the label 'wider' was dropped officially. While knowledge and skills are specific instruments and resources that one needs to have in one's toolbox, they do not tell much about when to use them or not use them. Responsibility and autonomy however relate to the contexts when and how one is expected to act proactively, which in the case of a humanitarian qualifications framework can be expected to receive much attention.

\section{The EQF Levels}

The EQF levels are intended to cover the entire span of qualifications commonly in existence, ranging from level 1 indicating the level upon completion of compulsory primary education, up to level 8 as the highest level of learning. As mentioned, the levels are applicable to general and adult education, vocational education and training, work contexts as well as higher education. In the final version of the EQF Recommendation, ${ }^{39}$ all references to an explicit hierarchy of education programmes behind the levels were excluded, which also makes sense since the learning outcomes mentioned for each level define what that level of learning means and not so much the diplomas, certificates and degrees normally associated with such a level. However, when constructing a qualifications framework a basic idea of what each level of learning means in practice is indispensable. Based on the descriptions in the EQF and associated literature ${ }^{40}$ the EUPRHA Project broadly understood the EQF levels as follows:

38 "Recommendation of the European Parliament and of the Council of 23 April 2008 on the Establishment of the European Qualifications Framework for Lifelong Learning," sec. Annex I.

39 "Recommendation of the European Parliament and of the Council of 23 April 2008 on the Establishment of the European Qualifications Framework for Lifelong Learning."

${ }^{40}$ Markowitsch and Luomi-Messerer, "Development and Interpretation of Descriptors of the European Qualifications Framework," 38-40, 46; Coles and Oates, European Reference Levels for Education and Training. An Important Parameter for Promoting Credit Transfer and Mutual Trust, 12-16 \& 49-51; "Recommendation of the European Parliament and of the Council of 23 April 2008 on the Establishment of the European Qualifications Framework for Lifelong Learning." 


\begin{tabular}{|c|c|}
\hline Level 1 & $\begin{array}{l}\text { Level } 1 \text { qualifications are not occupation specific and are often } \\
\text { sought by those with no qualification in order to access unskilled, } \\
\text { highly supervised employment by operational routine, no scope } \\
\text { for taking decisions and that may include a further element of } \\
\text { training. Learning is normally developed during compulsory primary } \\
\text { education and contributes to general education but is also achieved } \\
\text { through adult learning programmes (including popular adult } \\
\text { education) and through non-formal and informal learning. }\end{array}$ \\
\hline Level 2 & $\begin{array}{l}\text { Level } 2 \text { provides access to unskilled employment that leaves some } \\
\text { scope for decision-making and taking action but is still highly } \\
\text { supervised and may include a further element of training. Some of } \\
\text { these qualifications are occupation specific but most recognise a } \\
\text { general preparation for work and study. Learning is usually based } \\
\text { in a school (lower secondary education), an adult education centre, } \\
\text { college, training centre or an enterprise. Learning can also develop } \\
\text { through non-formal means through work-based or popular adult } \\
\text { education in communities. }\end{array}$ \\
\hline Level 3 & $\begin{array}{l}\text { Qualifications at level } 3 \text { recognise a general education and skills } \\
\text { base suitable for many job functions and typically provide access } \\
\text { to semi-skilled employment, in which tasks are carried out under } \\
\text { direction, with limited experience of practice in a particular aspect } \\
\text { of work or study. Level } 3 \text { achievement reflects formal learning in } \\
\text { upper secondary education or basic training in an occupational field } \\
\text { and comprises adult education (including popular adult education } \\
\text { labour market training) in schools, colleges, training centres or } \\
\text { learning in workplaces as well as non-formal learning through work. }\end{array}$ \\
\hline Level 4 & $\begin{array}{l}\text { Level } 4 \text { provides access to employment in skilled, autonomous work } \\
\text { and entails supervisory and coordination duties. A person with this } \\
\text { level of qualification will usually have experience of work or learning } \\
\text { in a given field. Level } 4 \text { achievement typically reflects completion } \\
\text { of upper secondary education and some formal learning in post } \\
\text { compulsory education including labour market training and popular } \\
\text { adult education (medium vocational level). It takes place in a range of } \\
\text { institutions and takes the form of non-formal learning through work. } \\
\text { Level } 4 \text { qualifications also form the entry level to higher education. }\end{array}$ \\
\hline Level 5 & $\begin{array}{l}\text { Level } 5 \text { provides access to employment in highly skilled work or } \\
\text { to career progression through improved recognition of work } \\
\text { capabilities, as well as to job roles requiring managerial duties. High- } \\
\text { grade technicians achieve these qualifications that often bridge } \\
\text { secondary and tertiary education and training. Qualifications at } \\
\text { level } 5 \text { typically follow completion of a post-secondary learning } \\
\text { programme, such as apprenticeship together with post programme } \\
\text { experience in a related field (higher vocational level). In higher } \\
\text { education, level } 5 \text { is linked to the short cycle within the first cycle } \\
\text { of the European Higher Education Area. }\end{array}$ \\
\hline
\end{tabular}




\begin{tabular}{|l|l|}
\hline Level 6 & $\begin{array}{l}\text { Level } 6 \text { qualifications provide access to professional employment } \\
\text { opportunities and are often career entry qualifications for } \\
\text { professional and managerial work. People working as knowledge- } \\
\text { based professionals or in professional management positions (e.g. } \\
\text { first level programme managers) achieve these qualifications. } \\
\text { Learning at level } 6 \text { is often highly specialised and usually takes place } \\
\text { in higher education institutions. However, work settings also provide } \\
\text { a sufficiently demanding context. Level } 6 \text { is generally linked to } \\
\text { Bachelor degrees (first cycle in the European Higher Education Area). }\end{array}$ \\
\hline Level 7 & $\begin{array}{l}\text { Level } 7 \text { qualifications offer access to employment and to career } \\
\text { progression within the specialist (or closely related) field. Experts, } \\
\text { senior professionals and managers (e.g. second level programme } \\
\text { managers, managers of managers) achieve these qualifications. } \\
\text { Learning at level } 7 \text { is often highly specialised, usually takes } \\
\text { place in specialist higher education institutions and is generally } \\
\text { linked to Master degrees (second cycle in the European Higher } \\
\text { Education Area). }\end{array}$ \\
\hline Level 8 & $\begin{array}{l}\text { Level } 8 \text { qualifications offer access to employment opportunities } \\
\text { in specialised fields and career progression for those involved in } \\
\text { jobs requiring research skills and/or high level leadership. Study } \\
\text { for these qualifications mostly takes place in specialist higher } \\
\text { education institutions and is generally linked to Doctorate degrees } \\
\text { (PhDs, third cycle in the European Higher Education Area). Learners } \\
\text { achieving a qualification at level } 8 \text { have demonstrated a systematic } \\
\text { understanding of a field of study and mastery of the skills and } \\
\text { methods of research associated with that field. Learning at this level } \\
\text { is mostly independent of formal learning programmes and takes } \\
\text { place through self-initiated actions guided by high level experts. }\end{array}$ \\
\hline
\end{tabular}

Initially, the EUPRHA Project did not cover every level but only levels 4 up to 8 , thereby basically ranging from skilled, autonomous work at medium vocational level up to occupations requiring research skills and/or high level leadership or higher. As the lower EQF levels are often associated with more general forms of education, levels 1 to 3 were left out at first. Additionally, in the case of the humanitarian sector, it was thought that these levels could coincide to a certain extent with frameworks from adjacent sectors such as civil protection. However, later feedback from the sector highlighted the importance for humanitarian workers to have the full arch of humanitarian qualifications defined in order to be able to implement recognition of prior learning. Lastly, the simultaneous development of levels 1 to 3 in conjunction with the already targeted levels 4 to 8 also prevented potential future discontinuities and inconsistencies between level descriptors and will potentially facilitate transparency and clarity about entrance conditions to gain access to higher education based on informal and non-formal learning. 


\section{The initial construction of the Sectoral Qualifications Framework}

As a meta-framework, the European Qualifications Framework is highly abstract by necessity in the description of its levels in order to make it possible for sectoral qualifications frameworks and national qualifications frameworks to relate to it. To a large extent, this is also true for national qualifications frameworks in order to have a variety of disciplines and work fields to relate to these in turn. Sectoral qualifications frameworks however are faced with a certain balancing act between being concretely enough related to their sector and maintaining a neutral qualifications framework at the same time, i.e. not being overly prescriptive and delimiting on the content of educational programmes that train for achieving those qualifications. In other words, a diversity of formal and non-formal programmes appropriate and relevant to a sector should be able to relate to their sectoral qualifications framework in order to verify the levels of learning they aspire to.

Relating a qualifications framework to a sector requires that there is a certain consensus on what is part and parcel of that sector, what are considered adjacent disciplines and sectors and at the same time being aware of overlapping areas. For the EUPRHA Project, it meant that it was first necessary to define what humanitarian action is. In the humanitarian sector, some actors take a narrow view of what they consider humanitarian action to be, delimiting it to relief activities in the immediate emergency phase in natural disasters and conflicts. Other actors take a broader view by also including reconstruction and rehabilitation activities or even activities that border on those normally considered part of the adjacent development sector. At the same time, national traditions with regard to humanitarian assistance also influence what is perceived part of it and what not. Discussions between the 30 European countries represented in the EUPRHA Project brought different interpretations of humanitarian action to light. Diverging interpretations in some countries bordered for other countries more on social work or charity for instance.

While trying to remain aware of different traditions and interpretations, the EUPRHA Project agreed upon a joint interpretation of what was considered to be part of the humanitarian sector and what not. On the basis of the European Consensus on Humanitarian Aid, humanitarian action was understood as an organised set of actions oriented to protect, help and assist people in distress or need, based on certain ethical values and attitudes. In the project's view, it encompasses protecting human life and dignity, satisfying basic needs, alleviating suffering, protecting human rights and preventing and reducing future risks. To distinguish the project's efforts from other sectors, certain areas were excluded as not belonging to humanitarian action, 
such as medium to long term development, crises that are not humanitarian in nature, human rights education, as well as migration phenomena beyond humanitarian displacements. ${ }^{41}$ For the earlier phases of the project, this working definition sufficed. For constructing the content of the qualifications framework itself however, a more in depth analysis proved necessary concerning the type of skills and competences normally deemed relevant and essential for the humanitarian sector. With this aim a group of experts, both academics and practitioners within the project analysed the current trends in the sector and their impact in terms of new skills and competences required in the humanitarian field..$^{42}$

The joint definition of the academic and professional field of humanitarian action and identifying problematic issues at the beginning formed together the first step. The following methodological steps in the process were based on earlier Tuning experiences with sectoral qualifications frameworks. The initial steps included investigating professional profiles and the competences associated with them, as well as defining the levels of learning in relation to the sector. Subsequently, several cycles were performed by defining and redefining progressive learning outcomes for the different levels focusing on the descriptors knowledge, skills and responsibility/autonomy separately (a vertical approach), alternated by focusing on the different levels separately in order to ensure coherent lines between knowledge, skills and responsibility/ autonomy (a horizontal approach). The next step after the construction of the draft concerned consultations with the sector and stakeholders to verify the result with expectations from the field and receive feedback on the development of the qualifications framework. This input was then again used for further revisions of the draft. Due to the iterative approach, external consultations and revisions within the EUPRHA group often followed one another and helped to remain flexible towards incorporating new insights and important changes informed by the consultations.

During the project, periodical seminars with all EUPRHA partners were organised in order to present work in progress, to review texts in smaller groups, debate the way forward and particularly to maintain momentum. While the first seminar held in Bilbao was used to familiarise all EUPRHA partners with the objectives of the project, key concepts and the methodological departure points, as well as to identify problematic issues in the project and possible ways to solve them, the seminar in Warsaw nine months later

${ }^{41}$ EUPRHA Concept Paper.

${ }^{42}$ The outcome was summarised in the EUPRHA Report on the State of the Art that draws upon many reports and different documents that have been published during the last years. 
required everyone to jointly draft learning outcomes in small groups either organised by descriptor or by level. In preparation for this exercise, a wealth of materials was collected in the form of existing humanitarian competencies frameworks, education and training programmes (mainly European) that defined their resulting qualifications in terms of intended learning outcomes, and particularly a collection of job profiles and job announcements from humanitarian agencies in the field. In the latter case, most resources were selected from job announcements available on ReliefWeb in the month July 2012 (out of ca. 2000 postings).

For all these materials, approximate levels of learning were determined based on the qualifications intended to be achieved in the case of educational training, or the minimum required diploma and years of experience in the case of job profiles. In addition, all learning outcomes, job requirements and framework competences were classified under the descriptor labels knowledge, skills and wider competences in order to structure the collected materials as much as possible according to the EQF table template. As can be expected the materials turned out to be very diverse in terms of quality, elaborateness and relevance. To increase the materials' usefulness a further distinction was made between generic elements, humanitarian sector-specific elements and elements that could be classified as local context, organisationspecific job requirements or particular training specialisations.

On the one hand, this created a rich reference basis for drafting learning outcomes for the levels. On the other hand, it also made evident differences in the use of learning outcomes and competence-based job requirements. Generally, it was noticeable that the educational sector made more use of these kinds of descriptions than the humanitarian sector, and within the humanitarian sector bigger agencies more than smaller agencies. In addition, Anglo-Saxon organisations seemed more detailed and concrete in describing programmes and job requirements in terms of skills and competences than organisations with other backgrounds. Lastly, the collected materials appeared to be dominated mostly by EQF levels 6 and 7, and less by the other levels, possibly because positions at these levels are more likely to be advertised internationally compared to levels 4 and 5, or are more frequent compared to level 8.

At the beginning in Warsaw, the collected materials were mainly used for inspiration on what should be included and to have an initial reference point on how the levels could link to education and the labour market. To structure content further, existing competencies frameworks from the humanitarian sector were used as a first guide. Particularly the Core Humanitarian Competencies Framework developed by the Consortium of British Humanitarian Agencies (CBHA) as one of the last frameworks that 
received much attention and recognition was used to inform on what subjects would need to be covered in the different levels. As a result, the first draft used the competency domains developed by the CBHA as recurring dimensions whilst formulating a progressive scale from basic to more advanced levels of learning.

These outcomes also provided the first means to start initial consultations with organisations from the humanitarian field and experts on qualifications frameworks. Very important in this process resulted to be the consultation with MSF Spain. ${ }^{43}$ Whereas most available competencies frameworks from the sector paid relatively little attention to progressive levels of learning, MSF had been developing a comprehensive set of competences each elaborated into four progressive levels of learning intended for all MSF offices worldwide. ${ }^{44}$ The Barcelona-Athens Operational Centre of MSF integrated this set into an elaborate Performance Management System, which established competency profiles for the different job families in the organisation and provided detailed specifications of the minimal levels at which a certain competency was required to have been attained for a certain job position. ${ }^{45}$ Because of the established relationship between the competency profiles and the job positions in their International Field Function Grid, it also became possible to infer approximate relationships between the MSF competency levels and the EQF levels of learning described by the EUPRHA Project. Most importantly however, it also offered proof for the potential that the qualifications framework of the EUPRHA Project could function as a bridge between the humanitarian labour market and humanitarian education and training programmes.

\section{Towards a humanitarian action meta-profile}

Based on the experiences from the first consultations round, the following EUPRHA seminar in Dublin offered the EUPRHA partners the possibility to refine and recheck the first draft and improve upon it considerably, though still following the original format established in Warsaw. In Dublin however, initial ideas how a meta-profile for the humanitarian sector could inform and

${ }^{43}$ Interview with Mr Aitor Zabalgogeascoa, former director of MSF Spain, Bilbao 13 March 2013.

44 Dictionary of Competencies.

${ }^{45}$ MSF OCBA Performance Management System Handbook 12/2011; Field Matrix of Competencies. Competency Profiles Grouped by Levels of the International Field Function Grid (IFFG). 
link to the qualifications framework also became more pronounced. From a Tuning perspective, a meta-profile can be defined as "a representation of the structure and combination of competences which gives identity to a subject area" ${ }^{46}$ The meta-profile represents thus the core elements in terms of competences and can for instance make a degree programme identifiable and recognisable as pertaining to a specific academic area. ${ }^{47}$

To a certain degree, the competency domains developed by CBHA played this role during the writing of the first draft of the qualifications framework, although in reverse order by highlighting what kind of structure could be given to the combination of knowledge, skills and competence for the humanitarian sector. Normally, a meta-profile is constructed via a bottom-up approach by clustering competences into possible classifications to provide points of reference for further dialogue and reflection. ${ }^{48} \mathrm{~A}$ metaprofile can also highlight the linkages between competences and discern differences in importance between them. ${ }^{49}$ Ultimately the graphic representation can take many different forms. ${ }^{50}$ However, to use the CBHA competency domains as a straightforward basis for the construction of a humanitarian action meta-profile seemed to overstretch its original use too much. Even though these competency domains were formulated on the basis of a relatively broad consensus of the humanitarian work field concerning which competences were deemed essential for every humanitarian aid worker ${ }^{51}$ it nevertheless represented only one effort in the humanitarian field to come to a coherent set of humanitarian competences.

Over the years, many different competencies frameworks relevant for humanitarian action have been developed: some developed for specific organisations or target groups, some focusing in particular on specific technical areas within humanitarian action, some specifying competences for specific roles in the humanitarian system, while other frameworks do not necessarily have a true humanitarian focus but could be considered relevant or at least informative by being in use among agencies of high importance to the sector. Competencies frameworks (most publicly available) that have been developed over the years for the humanitarian sector, or have at least relevance for the sector, concern:

${ }^{46}$ González and Yarosh, "Building Degree Profiles," 51.

47 Ibid., 50.

${ }^{48}$ Hahn and Teferra, "Tuning as Instrument of Systematic Higher Education Reform and Quality Enhancement: The African Experience," 151.

${ }^{49}$ González and Yarosh, "Building Degree Profiles," 51.

${ }^{50}$ Ibid., 53-61.

${ }^{51}$ Core Humanitarian Competencies Framework. Keeping Crisis-Affected People at the Centre of What We Do. 


\begin{tabular}{|ll|}
\hline \multicolumn{2}{|c|}{ Competencies frameworks relevant for humanitarian action (with approximate years of origin) ${ }^{52}$} \\
\hline 2003 & CARE USA \\
2005 & Humanitarian Logistics Association \\
2006 & Emergency Capacity Building Project \\
2007 & People in Aid \\
2008 & Australian Qualifications Framework (World Vision) \\
2009 & IASC Humanitarian Coordination Competencies \\
2009 & UNICEF Competencies \\
2010 & UN/OHRM \\
2010 & DFID Core Competency Framework \\
2010 & ELRHA Humanitarian Core Competencies \\
2010 & Child Protection In Emergencies \\
2010 & Public Health Preparedness \& Response \\
2010 & MSF Dictionary of Competencies \\
2012 & CBHA Core Humanitarian Competencies \\
2012 & World Vision Integrated Competency Development \\
2012 & Nutrition in Emergencies Competency Framework \\
\hline
\end{tabular}

Although this list cannot be considered exhaustive, several have performed important roles in shaping the debate on humanitarian competencies and the sector's quest towards further professionalisation.

\section{From a humanitarian action meta-profile to a qualifications framework}

The development of a comprehensive though essential meta-profile for humanitarian action was based on the analysis of this diverse collection of humanitarian competencies frameworks elaborated by the sector. In the last years the humanitarian sector had developed a rich range of often detailed competencies frameworks which had to be taken into consideration to avoid duplication of efforts. There was no need to reinvent the humanitarian competencies when there was already a broad support for the existing frameworks from the different humanitarian stakeholders. This was done through several consecutive steps:

1. Collecting the relevant existing frameworks for humanitarian action and mapping for each framework the set of competencies together with their descriptions (whenever available). ${ }^{53}$

2. In conformity with previous reports ${ }^{54}$ differentiating between core or person-based competences versus specialist or technical competences (in most cases found in specialised competencies frameworks).

${ }^{52}$ A link to all these competencies frameworks can be found at: "EUPRHA Library."

${ }_{53}$ The graphic result of the mapping exercise is available at: Ibid.

${ }^{54}$ Cf. Humanitarian Competencies Study, 5; Introduction to Local Level Staff Competencies; DFID Core Competency Framework. 
3. Focusing on the frameworks that already apply a certain clustering, while keeping unsorted frameworks separate at first.

4. Ordering the collected frameworks from purely humanitarian and widely accepted (most relevant) to more general humanitarian-related or discipline specific frameworks (relatively less relevant).

5. Making a first clustering of all encountered competencies by identifying competencies that have been designated by their frameworks as core, as these are most likely candidates to recur in all frameworks. Determining next under which cluster labels these core competences have been classified by the more purely humanitarian frameworks and clustering similar cluster labels together. This resulted in four 'core' clusters. Each received provisional labels based on the underlying cluster labels: 'commitment to principles', 'team relations / teamwork and cooperation', 'results and quality orientation / operational decisionmaking' and 'coping / pressure tolerance / behavioural flexibility'. Subsequently, adding competences from the unsorted frameworks that could be directly linked to these 'core' clusters.

6. Making a second clustering among the remaining groups of competencies by identifying whether additional 'core clusters' could be established, for instance in case two or more clusters were similar and could be supplemented with similar unsorted competencies. Four additional clusters could be identified this way: 'leadership', 'communication', 'safety' and 'thinking'.

7. Reordering within each newly formed cluster the competencies into sub themes and arranging these sub themes from more to less linked to the central theme of that group.

8. Cleaning up by reassigning outlying (less linked) competencies to more related groups, whenever opportune, and assigning the last leftover competencies.

9. Diminishing overlap between the sub themes and consolidating small clusters ('communication', 'safety') into related bigger clusters where feasible and opportune.

The results were fairly close to the dimensions identified in the CBHA domains, but several issues required further consideration. For instance, few among the frameworks identify a dimension related to the 'humanitarian context'. While the CBHA framework contains a clear reference to it, some other frameworks seem to allude to it somewhat in the form of maintaining situational awareness or maybe even political acumen. On the other hand, a relatively small but important cluster of competences centred around 'thinking and learning' emerged from the analysis without having a direct 
equivalent in the CBHA framework. Interestingly, different frameworks seem to value different forms of thinking, with analytical thinking being the most frequent. Both 'humanitarian context' and 'thinking and learning' lacked sufficient support among the collection of competencies frameworks to constitute a separate dimension and were relatively difficult to link unambiguously to one of the other dimensions. As a result, a pragmatic judgement call was made to combine these under a separate dimension labelled 'context analysis and reflection'. This had the added advantage to also facilitate a bridge toward activities in humanitarian research and education.

Another issue that required further attention concerned 'leadership'. In the case of 'safety and protection', it was relatively easy to argue in favour of combining it with 'coping behaviour' into a separate dimension, and in the case of 'communication' to subsume it under the broader dimension of 'collaborative relationships', but 'leadership' remained rather ephemeral in what it should comprise and in particular what not. To a certain extent, most potential sub themes of a 'leadership' dimension could also be argued to belong to one of the already established dimensions. However, 'leadership' figured prominently in most of the competencies frameworks and not recognising its essential importance for the humanitarian sector as a separate dimension seemed unjustifiable. As a consequence, 'leadership' was maintained visibly as a separate dimension, even though some closely related sub themes ended up under one of the other dimensions as being more appropriate there.

In the end, the dimensions analysis resulted into six main dimensions, each with several sub themes and links to the competences existing in the different humanitarian competencies frameworks. The latter provides the potential for the meta-profile to act as a translation device between different competencies frameworks and thus their organisational contexts. As for the graphic representation of the six dimensions and their respective interrelationships, an earlier analysis of the CBHA domains and linkages between them had already led to the recognition that such a representation could easily lead to a complex and sometimes debatable picture not contributing to a better grasp of the sector's essential characteristics. To a reasonable extent, the six dimensions could be ordered in sequential themes, but establishing the possibility of a hierarchical ordering was more precarious.

This concerned in particular the two dimensions 'humanitarian commitment' and 'service to crisis-affected people'. 'Humanitarian commitment' includes commitment to the humanitarian principles that pervade the humanitarian sector, define it and set it apart from other sectors with ambitions to provide assistance. In particular expressed by the International 
Red Cross and Red Crescent Movement, ${ }^{55}$ these principles are often hotly debated, sometimes misinterpreted, challenged, deviated from and threatened but considered absolutely key to the modus operandi of the sector at large. The first and most important principle concerns the humanitarian imperative that relates to the prime motivation behind humanitarian action, namely to alleviate human suffering wherever it may be found. Thus, the essence of the dimension 'humanitarian commitment' could be viewed as being of the highest order that structures and motivates all other dimensions.

Nonetheless, since the central goal is to alleviate suffering among crisisaffected people, it could equally be argued that all dimensions are instrumental to what is ultimately delivered by the dimension 'service to crisis-affected people'. Depending on whether the fundamental points of departure are stressed or the final cause, the choice leads to a different hierarchical ordering. For that reason, the visual rendering of the meta-profile tries to express these two different points of gravity by portraying 'humanitarian commitment' as a smaller but higher dimension and giving central stage to the dimension 'service to crisis-affected people':

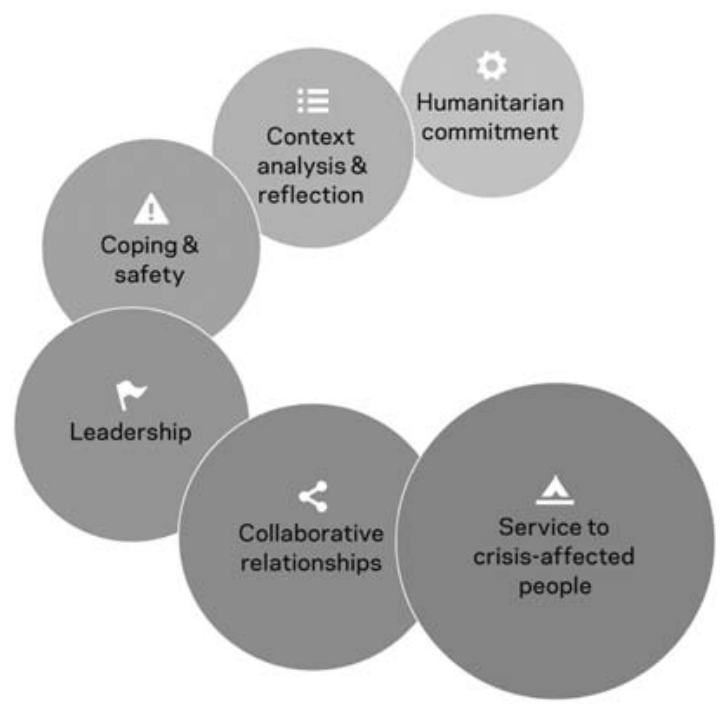

Figure 1

EUPRHA Meta-profile

${ }^{55}$ See: Code of Conduct for the International Red Cross and Red Crescent Movement and Non-Governmental Organizations (NGOs) in Disaster Relief; "The Fundamental Principles of the International Red Cross and Red Crescent Movement." 
In this meta-profile, the six dimensions that resulted from the analysis of humanitarian competencies frameworks group together several related subdomains and build upon underlying sets of competences as shown in the figure below:

- 'Humanitarian commitment' comprises in the meta-profile both a commitment to the general humanitarian principles, appreciation of existing humanitarian standards and codes, a professional commitment to the mission of one's humanitarian agency, as well as maintaining one's ethical integrity and respect for all human beings in their diversity. ${ }^{56}$

- 'Context analysis and reflection' refers to an understanding and situational awareness of the humanitarian context, as well as the need to analytically analyse its complexities and critically reflect upon one's actions in this context in order to learn for the future. ${ }^{57}$

- 'Coping and safety' encompasses in the meta-profile a humanitarian's self-awareness, adapting behaviour, coping with stress and resilience in the changing internal and external environment of a humanitarian agency, together with maintaining the safety of one's own person, one's team and one's agency against the threats and risks of humanitarian emergency situations, as well as contributing positively to the preparedness and protection of crisis-affected people. ${ }^{58}$

${ }^{56}$ Cf. Core Humanitarian Competencies Framework. Keeping Crisis-Affected People at the Centre of What We Do; Dictionary of Competencies; UNICEF Competency Definitions; DFID Core Competency Framework; Swords, Behaviours Which Lead to Effective Performance in Humanitarian Response. A Review of the Use and Effectiveness of Competency Frameworks Within the Humanitarian Sector; Walker and Russ, Professionalising the Humanitarian Sector, 34-38; Child Protection in Emergencies (CPIE) Competency Framework; Competency Development Planning Guide; UN Competency Development - a Practical Guide; Public Health Preparedness \& Response Core Competency Model; Knowledge, Skills, and Attitudes (KSAs) for the Public Health Preparedness and Response Core Competency Model.

57 Cf. Core Humanitarian Competencies Framework. Keeping Crisis-Affected People at the Centre of What We Do; Public Health Preparedness \& Response Core Competency Model; Knowledge, Skills, and Attitudes (KSAs) for the Public Health Preparedness and Response Core Competency Model; Dictionary of Competencies; Humanitarian Coordination Competencies; Humanitarian Competencies Study; UNICEF Competency Definitions; Introduction to Local Level Staff Competencies; Walker and Russ, Professionalising the Humanitarian Sector, 34-38; UN Competency Development - a Practical Guide.

${ }^{58}$ Cf. Core Humanitarian Competencies Framework. Keeping Crisis-Affected People at the Centre of What We Do; Dictionary of Competencies; Competency Development Planning 
- 'Leadership' focuses specifically on guiding, motivating, coaching and empowering others with authority in combination with establishing a clear vision, political acumen and strategic decision-making. ${ }^{59}$

- 'Collaborative relationships' in this meta-profile centres on working with others, both internal and external to one's organisation, in the form of teamwork, partnerships and networking activities, and includes cooperation and communication aspects, such as cultural sensitivity, trust-building and commitment, negotiation, influencing, advocacy, showing accountability and customer orientation. ${ }^{60}$

- 'Service to crisis-affected people' addresses the performance, professionalism and quality enhancement of one's services, based on needs assessment and service orientation, and includes the setup of operations in terms of problem solving capacity, creative

Guide; Humanitarian Coordination Competencies; UNICEF Competency Definitions; Swords, Behaviours Which Lead to Effective Performance in Humanitarian Response. A Review of the Use and Effectiveness of Competency Frameworks Within the Humanitarian Sector; Public Health Preparedness \& Response Core Competency Model; Knowledge, Skills, and Attitudes (KSAs) for the Public Health Preparedness and Response Core Competency Model; Child Protection in Emergencies (CPIE) Competency Framework; Walker and Russ, Professionalising the Humanitarian Sector, 34-38; Humanitarian Competencies Study; Introduction to Local Level Staff Competencies.

$59 \mathrm{Cf}$. Dictionary of Competencies; Walker and Russ, Professionalising the Humanitarian Sector, 34-38; Child Protection in Emergencies (CPIE) Competency Framework; "Humanitarian Logistics Certification Program: Competence Model Approach"; UNICEF Competency Definitions; UN Competency Development - a Practical Guide; Introduction to Local Level Staff Competencies; Competency Development Planning Guide; Humanitarian Coordination Competencies; Public Health Preparedness \& Response Core Competency Model; Knowledge, Skills, and Attitudes (KSAs) for the Public Health Preparedness and Response Core Competency Model; Core Humanitarian Competencies Framework. Keeping Crisis-Affected People at the Centre of What We Do; Humanitarian Competencies Study.

${ }^{60}$ Cf. Core Humanitarian Competencies Framework. Keeping Crisis-Affected People at the Centre of What We Do; Competency Development Planning Guide; DFID Core Competency Framework; Dictionary of Competencies; Walker and Russ, Professionalising the Humanitarian Sector, 34-38; Humanitarian Coordination Competencies; Introduction to Local Level Staff Competencies; Humanitarian Competencies Study; Swords, Behaviours Which Lead to Effective Performance in Humanitarian Response. A Review of the Use and Effectiveness of Competency Frameworks Within the Humanitarian Sector; UNICEF Competency Definitions; UN Competency Development - a Practical Guide; Public Health Preparedness \& Response Core Competency Model; Knowledge, Skills, and Attitudes (KSAs) for the Public Health Preparedness and Response Core Competency Model; "Humanitarian Logistics Certification Program: Competence Model Approach." 
innovation, initiative, facilitating change, decision making, planning \& organisation and the subsequent implementation of operations in terms of project management, financial management and working accountably. ${ }^{61}$ Linked to this dimension are specialised technical and professional expertise, which in several cases have been elaborated into more specialised competencies frameworks. ${ }^{62}$

Having the identified dimensions linked to underlying humanitarian competencies frameworks also gives the opportunity to identify alternative definitions for these dimensions and their sub themes, which offers on the one hand flexibility to adapt the dimensions to more specific contextual needs but also to investigate related skills and competences from multiple angles. Lastly, the links to the competencies of the different humanitarian frameworks also allow anyone to go more into depth than the end result of the EUPRHA Project, by necessity, will allow for.

Having verified the main dimensions relevant to the humanitarian sector provided the possibility to determine to what sectoral content the qualifications framework should refer to. Following the recent examples of the sectoral qualifications framework for the Humanities and for the Creative and Performing Disciplines, ${ }^{63}$ the EUPRHA Project developed for each dimension learning outcomes for the EQF levels 4, 5, 6, 7 and 8. In order to ensure horizontal readability between the columns, these learning outcomes were developed both in terms of knowledge, skills and responsibility/autonomy.

${ }^{61}$ Cf. Core Humanitarian Competencies Framework. Keeping Crisis-Affected People at the Centre of What We Do; Dictionary of Competencies; Introduction to Local Level Staff Competencies; Humanitarian Competencies Study; UNICEF Competency Definitions; Competency Development Planning Guide; DFID Core Competency Framework; Swords, Behaviours Which Lead to Effective Performance in Humanitarian Response. A Review of the Use and Effectiveness of Competency Frameworks Within the Humanitarian Sector; UN Competency Development - a Practical Guide; Walker and Russ, Professionalising the Humanitarian Sector, 34-38; "Humanitarian Logistics Certification Program: Competence Model Approach"; Public Health Preparedness \& Response Core Competency Model; Knowledge, Skills, and Attitudes (KSAs) for the Public Health Preparedness and Response Core Competency Model; Humanitarian Coordination Competencies.

${ }^{62}$ E.g. "Humanitarian Logistics Certification Program: Competence Model Approach"; Meeker et al., "Development of a Competency Framework for the Nutrition in Emergencies Sector"; Child Protection in Emergencies (CPIE) Competency Framework; Public Health Preparedness \& Response Core Competency Model; Knowledge, Skills, and Attitudes (KSAs) for the Public Health Preparedness and Response Core Competency Model; DFID Core Competency Framework; UNICEF Competency Definitions.

${ }^{63}$ Tuning Sectoral Qualifications Frameworks for the Humanities and the Arts. Final Report 2010-2011, 14-21 and 30-37. 
That way a logical relation was produced between what you should know at a certain level concerning one of the dimensions, what you should be able to do having that knowledge, and in what kind of contexts you should be able to work in making use of those skills and knowledge. The result was the EUPRHA Profile describing for each level in a separate table the knowledge, skills and responsibility/autonomy per dimension. ${ }^{64}$

Particularly for setting up education training programmes at a certain level, this elaborated sector profile is a helpful aid and reference point. It provides for each level of learning, guidance on what this can be expected to mean for the main aspects of humanitarian aid work. Depending on the objective of a programme, it can be supplemented with more specific, technical and/or professional elements relevant to the field.

The development of the meta-profile and its detailed elaboration into a sector profile expressed in the form of knowledge, skills and competence per dimension raised the question whether this could already be considered a qualifications framework as understood in the context of the European Qualifications Framework for Lifelong Learning. In this sense, a tension was noted between the abstract and general nature of the European and national qualifications frameworks that are intended to encompass all disciplines and sectors, versus sectoral qualifications frameworks that are expected to take into account the specific characteristics of a sector. As mentioned before, the risk of addressing sectoral characteristics is that enumerating all could possibly lead to a situation where an education programme would see itself compelled to include all characteristics, leaving (too) little room to distinguish itself from other programmes in the same sector. This would mean an undesired loss in educational variety and diversity and is not part of the ideas behind qualifications frameworks. In the end, a qualifications framework is meant to set standards for the progressive levels of learning, but not so much to set a pre-defined curriculum.

Therefore, in contrast to the sectoral qualifications framework developed for the Humanities and Performing Arts, only the most salient and generally indicative elements of the developed profile and its dimensions were selected and used for the qualifications framework. This meant a relaxation of the initial idea to have the dimensions covered at each level in terms of knowledge, skills and competence, but the fact that the qualifications framework was based on a profile structured by the meta-profile dimensions still secured the required horizontal readability between the columns knowledge, skills and responsibility/autonomy.

${ }^{64}$ The EUPRHA Profile and the Humanitarian Action Qualifications Framework are available on the EUPRHA website www.euprha.org, 


\section{Discussion}

The development of the Humanitarian Action Qualifications Framework and its underlying EUPRHA Profile and meta-profile is heavily grounded in pre-existing competencies frameworks. The participation of higher education representatives from thirty European countries in the project has helped to get the necessary traction and involvement among European educators. The same has been accomplished for the humanitarian sector through direct involvement from the humanitarian umbrella organisation ICVA and the Sphere Project, renowned for its work on setting humanitarian standards and principles, as well as from field practitioners through the NOHA Alumni Community ${ }^{65}$ However, the ultimate aim is that the framework is accepted by the humanitarian community at large. Therefore, the next stage is to reach as many users as possible in order that the project will continue to invite relevant groups for an open dialogue on the refinement and update of the qualifications framework and its applications.

At first thought, it seems that the primary users of the Humanitarian Action Qualifications Framework will be the educators and agencies in the humanitarian sector contending with own qualifications systems and competencies frameworks. By linking their own education and training programmes to the levels in the Humanitarian Action Qualifications Framework, they are better able to communicate with employers, prospective students, professional, statutory and regulatory bodies and other stakeholders how their qualifications compare to qualifications from other countries and different humanitarian education and training systems. As a result, employers that are recruiting humanitarian aid workers will be better equipped to assess differences in levels among the qualifications of prospective candidates, and humanitarian aid workers will be better equipped to explain the extent of their humanitarian action learning.

But this is only one part of the story. Qualifications play an important role in controlling access to and practice of tasks, professions and occupations. This control function is frequently motivated by safety and quality assurance requirements. It is, for example, widely accepted that welding of bridges and treatment of patients both involve risks and require clear and high quality standards. In the field of humanitarian action as former United Nations Under-Secretary-General for Humanitarian Affairs and Emergency Relief

${ }^{65}$ To increase further recognition and acceptance the project has presented its outcomes in a series of humanitarian and educational conferences and meetings (e.g. the Humanitarian Partnership Conference in Nairobi, the World Conference on Humanitarian Studies in Istanbul, the NOHA@20 Alumni Event in Brussels and many different occasions on national level in the different European countries). 
Coordinator Jan Egeland noted, “... if you're not a professional in this game, you have no right to descend on someone in their moment of crisis and do on-the-job training [...] Because the poor, dispossessed and disaster-prone should have at least one basic right left to them: to be protected from incompetence." ${ }^{66}$ However, in other cases use of qualifications to control access and practice may be linked to particular interests of professional groups and bodies. Controlling numbers of practitioners in a profession can be important to safeguard salaries and working conditions, but should not result into an exclusive 'membership club'.

During the project, the Humanitarian Action Qualifications Framework also raised questions concerning its European origin, even though its vocation is international, or better global. It should be of interest to non-European and global humanitarian actors and educators. On the one hand, the origins and methodology used are decidedly European, but its content in terms of learning outcomes is based on the humanitarian sector globally. As such, the framework can be used outside Europe to the extent that it is contextualised and adapted to the specific non-European needs. With the development of connections between regional meta-frameworks, this process might even become easier. ${ }^{67}$

Another concern that was raised several times relates to how the progression of learning in the qualifications framework can in the end be assessed. Of course, the framework is expressed in qualification learning outcomes and not in individual learning outcomes that can be assessed directly. For that it is necessary to translate these into training programme learning outcomes first. Having said that, the framework categorises qualification learning outcomes into knowledge, skills and responsibility \& autonomy, each of which may require different ways of assessment. Where traditional written exams may often suffice for testing theoretical and factual knowledge and understanding, assessing skills will frequently require a more applied ways of testing, particularly where it concerns practical skills, and testing responsibility \& autonomy might be more adequate by means of for instance simulations. As a follow-up on the EUPRHA Project, the translation and contextualisation of the qualifications framework into training programmes and subsequent assessment of achieved learning is a logical and highly useful next step, particularly in the light of certification attempts by the sector to recognise informal and non-formal learning. Moreover there is a need to link it to the recently developed classification system of European Skills, Competences, Qualifications and Occupations (ESCO).

${ }^{66}$ Herlinger, "Saving Human Lives Is No Place for Amateurs. An Interview with Jan Egeland," 180.

${ }^{67}$ Cf. Keevy, Chakroun, and Deij, Transnational Qualifications Frameworks, 2010. 


\section{Conclusion}

The relevance of the Humanitarian Action Qualifications Framework lies in the fact that it can act as a translating device to make national and sectoral qualifications more readable and promote humanitarian workers' and learners' mobility between countries and organisations. Through its descriptors and levels, it facilitates inter-system transparency and recognition of (non-) formal and informal learning by linking occupations, skills \& competences and qualifications, thus benefiting the humanitarian sector as a whole - humanitarian actors, educators, policy makers, students, volunteers, and the society at large - in an effort to further professionalise assistance to crisis-affected people. The Humanitarian Action Qualifications Framework addresses five purposes in particular:

1. to provide important points of reference for setting and assessing learning standards to humanitarian education providers,

2. to inform international comparability of humanitarian education and training standards in the European context and where possible beyond that,

3. to assist in the identification of potential progression routes for lifelong learning in humanitarian action,

4. to promote a shared and common understanding of the expectations associated with typical qualifications by facilitating a consistent use of qualification titles across the humanitarian and educational sector, and

5. to support workers' and learners' mobility.

The importance of the elaboration of this transparency tool rests in the fact that it serves as a context in which the different humanitarian professions with their profiles, competences, skills and levels can be articulated, thus helping with cross-border and cross-sector recognition of diplomas, training, work experience and formal and informal learning in the future. Earlier initiatives within the humanitarian sector on this topic clearly show that there is a strong need for this. In close discussion with main actors of the humanitarian sector, the EUPRHA Project has integrated these earlier initiatives in its work but specifically adds to this a more developed distinction between levels of learning, thereby also providing a stronger connection between the educational system and the humanitarian sector. A stronger connection is important both for quality assurance in the educational system and for the professionalisation demand of the humanitarian sector. The experience gained with the project process shows that there is a high complexity in purpose, type, coverage and competent bodies involved and 
the outcome of the project can just be considered the start of a new phase. Ultimately, this is all in the attempt to better serve people affected by humanitarian crises: the main people for whom this project is created and who, unfortunately are too many in our world. The best result would be if they feel a higher quality in the humanitarian service even though they may not know where this comes from.

\section{Bibliography}

Borton, John. Future of the Humanitarian System: Impacts of Internal Changes. Humanitarian Horizons. Berkhamsted, UK, November 2009. http://www. humanitarianfutures.org/wp-content/uploads/2013/06/2009-Future-of-theHumanitarian-system-impact-of-internal-changes.pdf.

Child Protection in Emergencies (CPIE) Competency Framework. Inter-agency Initiative of the Child Protection Working Group, 2010. http://www. unicefinemergencies.com/downloads/eresource/docs/2.6\%20Child $\% 20$ Protection/Inter-agency_CPIE_Competencies_Final_colour-1\%5B1\%5D.pdf.

Code of Conduct for the International Red Cross and Red Crescent Movement and Non-Governmental Organizations (NGOs) in Disaster Relief. Geneva: IFRC \& ICRC, 1994. http://www.icrc.org/web/eng/siteeng0.nsf/htmlall/code-ofconduct-290296.

Coles, Mike, and Tim Oates. European Reference Levels for Education and Training. An Important Parameter for Promoting Credit Transfer and Mutual Trust. Study commissioned to the Qualifications and Curriculum Authority, England. CEDEFOP Zones of Mutual Trust, March 2004. http://www.cpi.si/files/CPI/ userfiles/Datoteke/Novice/EKO/Reference_levels_QCA_study_fnal_ provisional_version_15_July_2004.pdf.

Competency Development Planning Guide. CARE USA, 2003. http://careweb.care. org/help/devplan/CompBook.doc.

Core Humanitarian Competencies Framework. Keeping Crisis-Affected People at the Centre of What We Do. CBHA, 2012. http://www.thecbha.org/media/ website/file/Competencies_Framework_2012_colour.pdf.

"Council Resolution of 27 June 2002 on Lifelong Learning (2002/C 163/01)." Official Journal of the European Communities, no. C 163 (June 27, 2002). http://eur-lex. europa.eu/LexUriServ/LexUriServ.do?uri=OJ:C:2002:163:0001:0003:EN:PDF.

DAC Statistical Reporting Directives. OECD, November 12, 2010. http://www.oecd. org/dac/stats/38429349.pdf.

DFID Core Competency Framework. Department for International Development, UK government, August 30, 2010. https://www.gov.uk/government/uploads/ system/uploads/attachment_data/file/214008/competency-framework.pdf.

Dictionary of Competencies. Validated by the IDRH, confidential. MSF, April 28, 2011. EUPRHA Concept Paper. EUPRHA, March 2012. http://www.euprha.org/wpcontent/uploads/2012/08/EUPRHA-Concept-Paper.pdf. 
“EUPRHA Library.” Accessed March 6, 2014. http://www.euprha.org/library/.

"European Qualifications Framework.” Accessed March 2, 2014. http://ec.europa.eu/ eqf/home_en.htm.

European Qualifications Frameworks, National Qualifications Frameworks, Higher Education, State of Play. EUCEN, n.d. http://www.eucen.eu/EQFpro/ GeneralDocs/FilesFeb09/STATEofPLAY.pdf.

Explaining the European Qualifications Framework for Lifelong Learning. Luxemburg: European Commission, 2008. http://ec.europa.eu/eqf/ documents?id=74.

Field Matrix of Competencies. Competency Profiles Grouped by Levels of the International Field Function Grid (IFFG). MSF, 2012.

GHA Report 2012. Somerset, UK: Global Humanitarian Assistance, Development Initiatives, 2012. http://www.globalhumanitarianassistance.org/wp-content/ uploads/2012/07/GHA_Report_2012-Websingle.pdf.

González, Julia, and Maria Yarosh. "Building Degree Profiles. The Tuning Approach." Tuning Journal for Higher Education, no. 1 (November 2013): 37-69.

Hahn, Karola, and Damtew Teferra. "Tuning as Instrument of Systematic Higher Education Reform and Quality Enhancement: The African Experience." Tuning Journal for Higher Education, no. 1 (November 2013): 127-63.

Herlinger, Chris. "Saving Human Lives Is No Place for Amateurs. An Interview with Jan Egeland." In With Courage, in Hope. Five Years After the Tsunami, 175-80. Geneva: ACT International, 2009. http://issuu.com/actalliance/docs/withcourage-in-hope.

Humanitarian Competencies Study. Emergency Capacity Building Project, Staff Capacity Initiative, April 2006. http://www.ecbproject.org/downloads/resources/ humanitarian-competencies-study-report.pdf.

Humanitarian Coordination Competencies. Inter-Agency Standing Committee, 2009. http://www.humanitarianinfo.org/iasc/downloaddoc.aspx?docID=5090\&type=pdf.

"Humanitarian Logistics Certification Program: Competence Model Approach." Accessed March 3, 2014. http://www.hlcertification.org/mod/page/view. php?id=12.

Implementing the Community Lisbon Programme. Proposal for a Recommendation of the European Parliament and of the Council on the Establishment of the European Qualifications Framework for Lifelong Learning. Brussels: Commission of the European Communities, September 5, 2006. http://www. encore-edu.org/ENCoRE-documents/com_2006_0479_en.pdf.

International Qualifications. Luxemburg: CEDEFOP, 2012. http://www.cedefop. europa.eu/EN/Files/4116_en.pdf.

Introduction to Local Level Staff Competencies. Integrated Competency Development (ICD) Resources. World Vision International, 2012. http://www.wvi.org/ guidancefordevelopmentprogrammes.

"Joint Statement by the Council and the Representatives of the Governments of the Member States Meeting within the Council, the European Parliament and the European Commission (2008/C 25/01) The European Consensus on Humanitarian 
Aid." Official Journal of the European Union, no. C 25/1 (January 30, 2008). http://eur-lex.europa.eu/LexUriServ/LexUriServ.do?uri=OJ:C:2008:025:0001:0 012:EN:PDF.

Keevy, James, Borhene Chakroun, and Arjen Deij. Transnational Qualifications Frameworks. Draft. Torino: European Training Foundation, 2010.

- Transnational Qualifications Frameworks. Luxemburg: European Training Foundation, 2011. http://www.etf.europa.eu/webatt.nsf/0/720E67F5F1CC3E1DC 125791A0038E688/\$file/Transnational\%20qualifications\%20frameworks.pdf.

Knowledge, Skills, and Attitudes (KSAs) for the Public Health Preparedness and Response Core Competency Model. Association of Schools for Public Health (ASPH) \& the Centers for Disease Control and Prevention (CDC), September 2012. http://www.asph.org/userfiles/KSA.pdf.

Markowitsch, Jörg, and Karin Luomi-Messerer. "Development and Interpretation of Descriptors of the European Qualifications Framework." European Journal of Vocational Training, no. 42/43 (October 2007): 33-58.

Meeker, Jessica, Abigail Perry, Carmel Dolan, Colleen Emary, Kate Golden, Caroline Abla, Anne Walsh, Ali Maclaine, and Andrew Seal. "Development of a Competency Framework for the Nutrition in Emergencies Sector." Public Health Nutrition 17, no. 3 (2013): 689-99.

MSF OCBA Performance Management System Handbook 12/2011. MSF OCBA internal document. MSF, December 2011.

Multi-Stakeholder Meeting on the Creation of a Humanitarian Learning and Development Passport. Doha: ELRHA \& Qatar Foundation, 2012. http://www. elrha.org/uploads/Multi\%20stakeholder\%20 Meeting\%20 on\% 20 Humanitarian\%20Professionalisation-\%20Doha\%20Report.pdf.

Public Health Preparedness \& Response Core Competency Model. Association of Schools for Public Health (ASPH) \& the Centers for Disease Control and Prevention (CDC), December 27, 2010. http://www.asph.org/userfiles/Prepared nessCompetencyModelWorkforce-Version1.0.pdf.

"Recommendation of the European Parliament and of the Council of 23 April 2008 on the Establishment of the European Qualifications Framework for Lifelong Learning." Official Journal of the European Union, no. C 111/01 (May 6, 2008). http://eur-lex.europa.eu/LexUriServ/LexUriServ.do?uri=OJ:C:2008:111:0001:0 007:EN:PDF.

"SQF Humanities and Arts: Outcomes." Accessed March 4, 2014. http://www. unideusto.org/tuningeu/sqf-humanities-and-arts/outcomes.html.

Swords, Sara. Behaviours Which Lead to Effective Performance in Humanitarian Response. A Review of the Use and Effectiveness of Competency Frameworks Within the Humanitarian Sector. Research report. People In Aid, June 2007. http://www.peopleinaid.org/pool/files/pubs/competencies-report---final.pdf.

Taylor, Glyn, Abby Stoddard, Adele Harmer, Katherine Haver, Paul Harvey, Kathryn Barber, Lisa Schreter, and Constance Wilhelm. The State of the Humanitarian System. London: ALNAP, 2012. http://www.alnap.org/pool/files/ alnap-sohs-2012-lo-res.pdf. 
"The Fundamental Principles of the International Red Cross and Red Crescent Movement," October 31, 1986. http:/www.icrc.org/eng/resources/documents/redcross-crescent-movement/fundamental-principles-movement-1986-10-31.htm.

The State of Art of Humanitarian Action. A Quick Guide on the Current Situation of Humanitarian Relief, Its Origins, Stakeholders and Future. EUPRHA, 2013. http://www.euprha.org/wp-content/uploads/2013/09/EUPRHA-Report.-TheState-of-Art-of-Humanitarian-Action-2013.pdf.

“Tuning Educational Structures in Europe." Accessed March 3, 2014. http://www. unideusto.org/tuningeu/.

“Tuning Methodology." Accessed March 2, 2014. http://www.unideusto.org/ tuningeu/tuning-methodology.html.

Tuning Sectoral Framework for Social Sciences. Final Report Public Part. Bilbao: University of Deusto, Tuning SQF Project, August 15, 2010. http://www. unideusto.org/tuningeu/images/stories/sectoral_framework/2007_10347_FR_ Tuning_SQF_PUBLIC_PART.pdf.

Tuning Sectoral Qualifications Frameworks for the Humanities and the Arts. Final Report 2010-2011. Bilbao: Tuning Project, 2012. http://www.unideusto.org/ tuningeu/images/stories/HUMART/SQF_HUMART_Final_Report_2010-2011. pdf.

UN Competency Development - a Practical Guide. United Nations, Office of Human Resources Management, April 2010. http://www.un.org/staffdevelopment/ developmentguideweb/image/OHRM_CDG.pdf.

UNICEF Competency Definitions. UNICEF, 2009. http://www.unicef.org/about/ employ/files/UNICEF_Competencies.pdf.

Wagenaar, Robert. “Columbus' Egg? Qualifications Frameworks, Sectoral Profiles and Degree Programme Profiles in Higher Education." Tuning Journal for Higher Education, no. 1 (November 2013): 71-103.

Walker, Peter, and Daniel G. Maxwell. Shaping the Humanitarian World. Abingdon, Oxon: Routledge, 2008. http://books.google.nl/books?id=qvKSAgAAQBAJ\&d $\mathrm{q}=$ Walker,+Peter+and+Daniel+Maxwell+\%282009\%29+Shaping+the+Humani tarian+World+Abingdon:+Routledge \&lr=.

_ Evolving the Humanitarian Endeavour." International Review of the Red Cross 93, no. 884 (December 2011): 1193-1210. doi:10.1017/S1816383112000276.

- Professionalising the Humanitarian Sector: A Scoping Study. ELRHA, April 2010. http://www.elrha.org/uploads/Professionalising_the_humanitarian_ sector.pdf. 